\title{
Early childhood caries and malnutrition: baseline and two-year follow-up results of a community-based prevention intervention in Rural Ecuador
}

\author{
Karen Sokal-Gutierrez ${ }^{1}$, Bathsheba Turton ${ }^{2 *}$, Hannah Husby ${ }^{3}$ and Cecilia Leonor Paz ${ }^{4}$
}

\begin{abstract}
Background: The global "nutrition transition" has increased children's consumption of sugary snacks and beverages (junk food), compounding their risk for poor oral health and malnutrition. The purpose of this study was to examine the relationship between early childhood caries (ECC) and malnutrition in a community context.

Methods: This is a baseline and two-year follow-up analysis of a community-based preventive oral health and nutrition intervention for 1,575 children, from birth through age six, in an indigenous population in rural Ecuador. Trained community volunteers, preschool teachers and dentists provided children and families with nutrition and oral health education, toothbrushes and fluoride toothpaste, fluoride varnish, and referral for dental treatment, three times per year. Annual data collection included mother interviews, child dental examinations and measurements of height and weight. Descriptive and bivariate analyses were completed in SPSS.

Results: At baseline, nearly half of children consumed junk food daily. ECC began in infancy, increasing steadily thereafter. Among one-year-olds, 53.8\% had caries with a mean of 2.1 decayed teeth; and among six-year-olds, 98.6\% had caries with a mean of 10.5 decayed teeth, and half experienced mouth pain. At two-year follow-up, reported junk food consumption was cut in half; and the prevalence and severity of caries and mouth pain were reduced. Children who entered the intervention in their first year of life experienced the greatest dental improvements. Children who entered in their first two years and attended the entire two-year intervention experienced a one-third reduction in stunting malnutrition, with greatest improvement among those whose caries increment was controlled.
\end{abstract}

Conclusions: ECC and caries-related malnutrition were reduced for children who participated in this prevention-oriented community oral health and nutrition intervention, especially those beginning in the first two years of life. Oral health and nutrition promotion should be incorporated into all maternal-child health programs, from pregnancy and birth onward.

Keywords: Oral health, Dental, Early childhood caries, Malnutrition, Maternal-child health, Community-based intervention, Ecuador, Indigenous

* Correspondence: Bethy.turton@gmail.com

¿University Puthisastra, Phnom Penh, Cambodia

Full list of author information is available at the end of the article

(c) The Author(s). 2016 Open Access This article is distributed under the terms of the Creative Commons Attribution 4.0 International License (http://creativecommons.org/licenses/by/4.0/), which permits unrestricted use, distribution, and reproduction in any medium, provided you give appropriate credit to the original author(s) and the source, provide a link to the Creative Commons license, and indicate if changes were made. The Creative Commons Public Domain Dedication waiver (http://creativecommons.org/publicdomain/zero/1.0/) applies to the data made available in this article, unless otherwise stated. 


\section{Background}

Child malnutrition remains one of the most prevalent global health challenges, with adverse consequences for children's health and educational potential [1]. Over recent decades, the global "nutrition transition"-a shift from the traditional diet (breastfeeding, agriculturalbased foods, regular meals) to the modern diet (bottlefeeding, processed sugary and non-nutritious foods/ drinks, frequent snacking) - has contributed to a "double burden" of under-malnutrition and overweight/obesity in low- and middle-income countries [2, 3].

Another consequence of the nutrition transition is the global pandemic of early childhood caries (ECC), or tooth decay, currently the most common chronic disease of childhood, affecting $60-90 \%$ of children worldwide [4]. While ECC is caused by a combination of an oral bacterial biofilm, the diet, and factors relating to the host such as tooth morphology or medical conditions [5], dietary sugars are considered the primary drivers of the progression of dental caries [6]. Numerous studies have demonstrated associations between dental caries and malnutrition-with under-nutrition in some populations, and obesity in other populations, depending on a complex set of socioeconomic and cultural characteristics $[7,8]$. Due to low political prioritization of oral health, most children have poor access to dental care, leaving most caries untreated, commonly leading to bacterial invasion of the pulp and tooth-supporting structures, chronic infection and mouth pain [9].

There are several hypothesized mechanisms by which dental caries can undermine children's nutrition and growth. Loss of tooth structure, mouth pain and chronic dental infection/inflammation can reduce children's appetite, impair chewing ability, disrupt children's sleep, affect glucocorticoid and growth factor regulation, and compromise metabolism and immunity [10-12]. Furthermore, studies show a bi-directional relationship between caries and malnutrition-children with malnutrition are prone to tooth enamel defects with greater vulnerability to caries; and children with severe caries are at increased risk for developing malnutrition [13]. The association between caries and obesity results from both diseases sharing common risk factors, such as frequent consumption of sugary foods and beverages [14].

While most studies on caries and malnutrition have been cross-sectional, some longitudinal studies providing dental treatment for children with severe caries and malnutrition demonstrated subsequent improvement in children's nutritional status [15]. However, there is a need for interventions to "move upstream" to demonstrate whether population-wide interventions designed to prevent early childhood caries from birth can also prevent caries-related malnutrition. Interventions such as the promotion of breastfeeding and healthy eating, tooth brushing with fluoride toothpaste, and the application of fluoride varnish have been shown to be effective, low cost [16], and deliverable by non-dental maternalchild health care providers [17].

Ecuador is a middle-income country, with higher rates of malnutrition and poorer access to health care services in rural and indigenous populations [17]. While Ecuador reduced the prevalence of chronic stunting malnutrition in children under age five from $40 \%$ in 1986 to $22-29 \%$ in studies from 2006-2013 [18-20], stunting rates of 30$50 \%$ persist in rural and indigenous populations, and Ecuador continues to have one of the highest malnutrition rates in Latin America [20]. Studies have also shown that Ecuador has among the highest rates of childhood caries in Latin America [21]. The 2009 national oral health survey found that $76 \%$ of children age 6-to15 had caries [20]. A study in the Amazonian region of Ecuador found that, among six-year-olds, 92\% of indigenous children and $95 \%$ of non-indigenous children had caries, with a mean of 6.4 and 8.4 decayed teeth respectively (i.e., approximately $1 / 3$ of their 20 total primary teeth) [22].

To date, the major global nutrition literature has not yet recognized ECC as a contributor to malnutrition, nor recommended ECC prevention as a strategy to prevent malnutrition [1]. The purpose of this study was to examine the cross-sectional and longitudinal relationship between ECC and malnutrition in the context of a community-based intervention designed to prevent ECC and malnutrition, starting from birth.

\section{Methods}

\section{Study design}

This paper reports selected quantitative results from the baseline (2011) and 2-year follow-up (2013) of a mixedmethods study to assess the feasibility, acceptability and efficacy of a community-wide preventive oral health and nutrition program for indigenous families with children from birth through age 6 in the Amazonian region of Ecuador. Only data from the 2011 and 2013 surveys were selected for presentation; data from 2012 are not presented. The program, Alli Kiru (beautiful teeth), was developed in collaboration with the community, and is part of a family of studies in five countries in Latin America and Asia. The study received approval by the Institutional Review Board at the University of California, Berkeley (2011-04-3178); as well as the leaders of the Pueblo Kichwa de Rukullakta community, the provincial directors from the local preschool and infant care programs, and Ministry of Health.

\section{Study population}

The study population is a convenience sample of children 6 months through 6 years of age and their mothers/caregivers living in Pueblo Kichwa de Rukullakta, an organized 
network of 17 rural indigenous Kichwa communities in the Amazonian Napo Province of Ecuador. The program aimed to include as many as possible of the estimated 1,000-1,500 preschool-aged children in the communities that agreed to participate. Each year, new babies were born into the study population, seven-year-olds were graduated out of the study population, and some families were lost to follow-up. Analysis was completed for the entire crosssectional sample, and for a longitudinal subsample who attended the baseline and two annual follow-up visits (Fig. 1). This population had some access to dental services through local Ministry of Health dental clinics.

\section{Participant recruitment and intervention}

Kichwa community volunteers and preschool/child care administrators invited all Kichwa families with children under 6-years to participate in the program on designated dates and locations (usually primary schools). Incentives for community volunteers and teachers included toothbrushes and fluoride toothpaste for themselves and their family, a small stipend for the community volunteers, and a toothbrush holder for each preschool/ child care classroom. Additional incentives for families included enrollment in a raffle of children's toys and clothes.

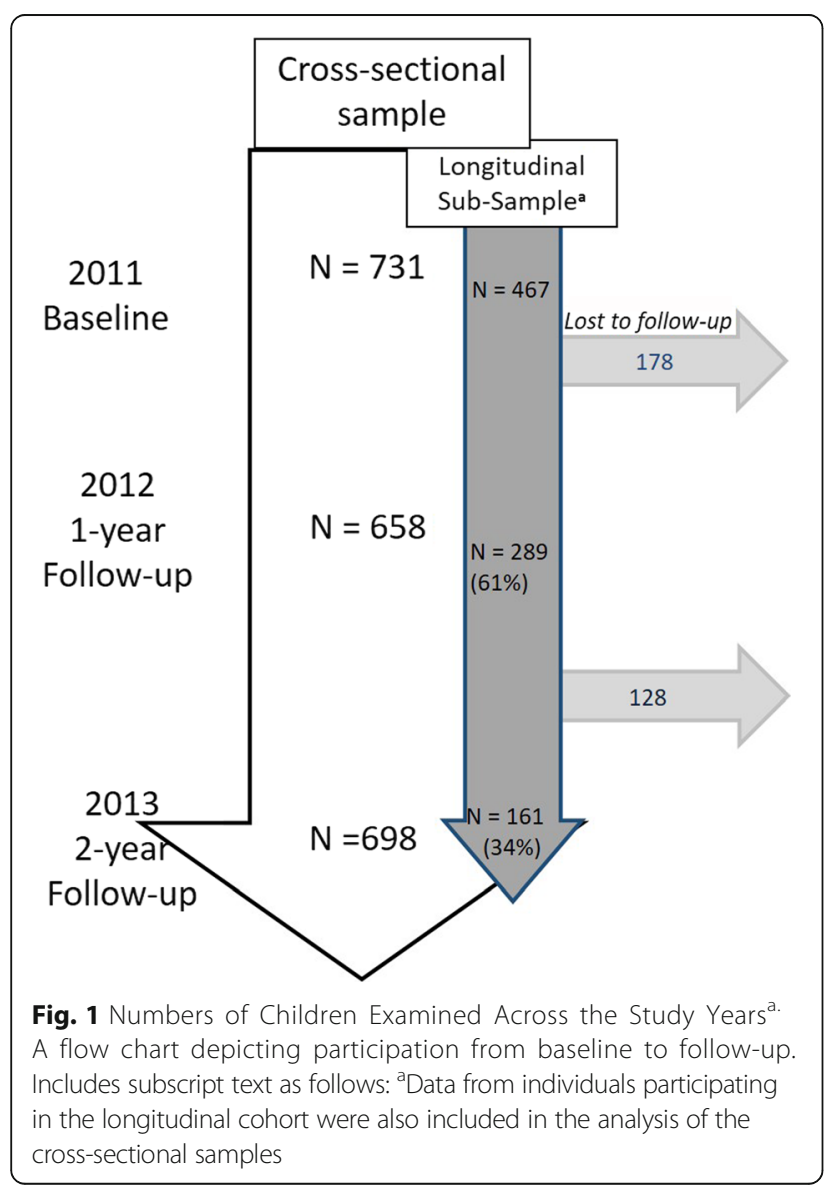

Mothers/caregivers provided written consent after receiving a consent form in Spanish and verbal explanation of the study in Kichwa or Spanish. Children received a simple verbal explanation of the procedures, and provided verbal assent.

Trained Kichwa community volunteers, preschool teachers and Ministry of Health dentists provided the intervention to children under 6-years and their mothers/caregivers, three times per year: (1) Nutrition and oral health education for children and families, in Kichwa and/or Spanish (2) Toothbrushes and fluoride toothpaste for all family members (3) Fluoride varnish applications to children's teeth and (4) Child dental screening, and onsite dental treatment or referrals for treatment, as needed.

\section{Data collection}

\section{Mother/caregiver interview} Interviews were conducted by trained Kichwa volunteers (for monolingual Kichwa-speaking caregivers) or fluent Spanish-speaking volunteers (for Spanish-speaking caregivers). The child's primary caregiver (usually the mother) was interviewed in her preferred language, in as private a setting as possible. The interview was comprised of 50 questions on family demographic characteristics, mother and child diet, oral hygiene and dental problems, medical and dental care utilization, and the caregiver's assessment of the child's oral health and overall health. The questions were adapted from global oral health surveys for a low-literacy population [23]. The frequency of the child's complaint of mouth pain was reported by the mother; and children reported to have mouth pain "occasionally," "frequently" or "almost always" were recorded as experiencing mouth pain, regardless of the cause. Aside from self-reported use of fluoride toothpaste and visits to the dentist, no data were collected on children's exposure to preventive measures (e.g., fluoridated water, fluoride rinse and gel and dental sealants).

2. Child dental examination Child dental examinations were conducted by licensed Ecuadorean and US dentists or a dental hygienist, with a trained assistant, by visual inspection only with a light and dental mirror. They recorded decayed, missing and filled teeth (dmft); and depth of cavitation by inspection: into tooth enamel only, into the dentin, and deep cavitation close to or in the pulp. The examiners did brief standardization of their examinations by independently and then jointly examining 5 children, and agreeing on the findings. 
3 Anthropometric measures

Children's height and weight were measured to assess their nutritional status. Trained volunteers measured and weighed children without shoes and in lightweight clothes, using a stadiometer and digital scale [24].

\section{Data analysis}

Data were recorded on paper forms, scanned using Remark Office OMR software (version 6.0.4) into a Microsoft Excel spreadsheet, and exported to IBM SPSS (version 19.0) for analysis. After cleaning, descriptive statistics were generated prior to undertaking bivariate analysis.

Children's dental caries experience was analyzed by the presence of any caries (i.e., any decayed teeth, missing teeth due to extraction, or filled teeth), and the extent or severity of caries as calculated by: a) The mean number of decayed, missing or filled teeth (dmft); b) The presence of deep cavitation; c) The "caries increment" defined as the number of new carious lesions per year, divided into tertiles for low (0-2 dmft/year), medium (3-5 dmft/year) and high caries increment ( $\geq 6 \mathrm{dmft} /$ year); and $\mathrm{d}$ ) The presence of mouth pain, as reported by the mother/caregiver.

Children's nutritional status was determined by the WHO 2006 growth standards (AnthroPlus software, version 1.0.3) to calculate height-for-age Z-score (HAZ) and weight-for-age Z-score (WAZ), with moderate/severe "stunting" or chronic malnutrition defined as HAZ $<-2 \mathrm{Z}$, and moderate/severe "underweight" defined as $\mathrm{WAZ}<-2 \mathrm{Z}$.

Differences among proportions were compared using the chi-squared $\left(\chi^{2}\right)$ test for unrelated samples and McNemar's test with Cochran's Q-test in related samples. Differences among means were compared using the Mann-Whitney $U$-test or the Kruskal-Wallis H-test (as appropriate) in unrelated data and the Wilcoxon signed rank test for related data.

\section{Results}

\section{Population characteristics}

A total of 1,575 children from age 6 months through 6 years participated in the population-based sample. This included 731 examined at baseline (2011), 658 children examined at 1-year follow-up (2012) and 698 children examined at 2-year follow-up (2013). Of the 467 children examined in 2011 who were age $0-4$ and age-eligible for 2 -year follow up (i.e., 6 years or less in 2013), 289 (61\%) were followed-up in 2012, and 161 (34\% of the initial sample) were followed-up in 2013, compromising the longitudinal subsample (Fig. 1).

The families' demographic characteristics were similar at baseline and follow-up (Table 1). The families were low-income with limited resources, including only 1 in 3
Table 1 Family Demographic Characteristics and Nutrition/Oral Health Practices

\begin{tabular}{|c|c|c|}
\hline & Baseline (2011) & $\begin{array}{l}\text { 2-year Follow-up } \\
\text { (2013) }\end{array}$ \\
\hline $\begin{array}{l}\text { Demographic } \\
\text { Characteristics }\end{array}$ & $\begin{array}{l}(N=321 \text { mothers, } \\
731 \text { children) }\end{array}$ & $\begin{array}{l}\text { ( } N=236 \text { mothers, } \\
698 \text { children) }\end{array}$ \\
\hline Child mean age, years & 3.5 (SD 1.9) & 3.7 (SD 1.8) \\
\hline Child gender, \%M, F & $53.7 \% \mathrm{M}, 46.3 \% \mathrm{~F}$ & $49.6 \% \mathrm{M}, 50.4 \% \mathrm{~F}$ \\
\hline $\begin{array}{l}\text { Child immunizations } \\
\text { up-to-date }\end{array}$ & $82.9 \%$ & $91.2 \%$ \\
\hline Mother age, years & 30.8 (SD 9.0) & $30.0(S D 8.5)$ \\
\hline Mother years of school & 7.8 (SD 4.5) & 9.3 (SD 3.6) \\
\hline Mother received prenatal care & $81.0 \%$ & $89.7 \%$ \\
\hline Number of children & 3.8 (SD 2.6) & 3.6 (SD 2.3) \\
\hline $\begin{array}{l}\text { Number living in the } \\
\text { household }\end{array}$ & 6.9 (SD 3.0) & 6.5 (SD 2.8) \\
\hline Potable water at home & $32.2 \%$ & $34.7 \%$ \\
\hline Electricity in home & $86.8 \%$ & $89.0 \%$ \\
\hline Cooks with non-wood fuel & $86.1 \%$ & $89.4 \%$ \\
\hline $\begin{array}{l}\text { Home located within a } 5 \text {-min } \\
\text { walk to a store that sells junk food }\end{array}$ & $70.6 \%$ & $77.1 \%$ \\
\hline \multicolumn{3}{|l|}{ Nutrition Practices } \\
\hline Child ever breast fed & $97.6 \%$ & $98.2 \%$ \\
\hline Child ever bottle fed & $37.9 \%$ & $33.8 \%$ \\
\hline $\begin{array}{l}\text { Child consumes any junk food } \\
\text { (e.g., candy, chips, ice pop, soda) } \\
\geq 1 / \text { day }\end{array}$ & $42.4 \%$ & $21.3 \%^{\mathrm{a}}$ \\
\hline \multicolumn{3}{|l|}{ Oral Health Practices } \\
\hline Mother brushes child's teeth & $78.4 \%$ & $78.7 \%$ \\
\hline Child ever been to the dentist & $66.1 \%$ & $66.0 \%$ \\
\hline
\end{tabular}

${ }^{\mathrm{a}} P=<0.001 x^{2}$ test

families having potable water. However, the majority of the population had rapid access to sugary snacks and beverages (Junk food)-approximately three out of four families lived within a five-minute walk to a store that sold junk food. At baseline, there were no significant differences in demographics between the cross-sectional sample and the longitudinal subsample; however the longitudinal subsample had a trend toward greater caries experience and a significantly higher prevalence of stunting malnutrition.

\section{Nutrition and oral health practices}

The population's nutrition/oral health practices exhibited strengths and risk factors, and most practices were similar at baseline and follow-up (Table 1). Nearly all children were breastfed, however approximately one-third were also bottle fed. At baseline, nearly half of children reportedly consumed junk food at least once a day, but by twoyear follow-up the proportion was cut in half. While nearly all mothers received prenatal care and nearly all 
children were up-to-date on their immunizations, only two out of three children had ever been to the dentist.

\section{Early childhood caries, mouth pain and malnutrition}

The population-wide experience of dental caries by age shows that ECC began within the first year of life (i.e., within 6 months of the eruption of the first teeth), increased dramatically over the first two-to three-years of life, and was a near-universal and severe disease experience by three-to six-years of age (Fig. 2). At baseline, over half of one-year-olds had caries; and at age six, 99\% of children had caries, with a mean dmft of 10.5 (i.e., $1 / 2$ of their teeth), including two in three children with deep caries, and one-half with mouth pain.

From baseline to two-year follow-up, there were substantial reductions in population-wide caries experience by caries prevalence, mean $\mathrm{dmft}$, and prevalence of deep decay and mouth pain. The greatest reduction in caries experience was found for the children who entered the intervention during infancy, and were age one-to threeyears at follow-up: one-year-olds' caries experience was cut by roughly one-half (caries prevalence from 53.8 to $30.3 \%$, and dmft from 2.1 to 0.9 ), and two-year-olds' caries experience was cut by roughly one-third (caries prevalence from 82 to $60 \%$, dmft from 5.3 to 3.0 , and deep caries from 19 to $12 \%$ ).

In the baseline sample, the prevalence of mouth pain tracked closely with the increasing prevalence and severity of caries by age. At baseline, one-half of six-year-olds experienced mouth pain; and by two-year follow-up, the prevalence of mouth pain in five-to six-year olds was reduced by half.
This population of children is seen to have a high prevalence of caries, mouth pain and malnutrition (Table 2). At baseline, the longitudinal subsample had a trend toward more severe caries experience, and a significantly higher prevalence of stunting (HAZ) malnutrition than the crosssectional sample $(43.0 \%$ vs. $34.7 \%, p=0.037)$. From baseline to follow-up, the cross-sectional and longitudinal samples showed significant reductions $(P=<0.05)$ or trends in reduction in caries experience and mouth pain; and the longitudinal subsample showed a significant reduction in stunting malnutrition by HAZ.

In the higher-risk longitudinal subpopulation, at baseline (2011), it can be seen that the "natural history" of stunting malnutrition by age showed a rate of $41 \%$ at age 1 , a peak of $61 \%$ at age 2 , a decrease to $40 \%$ at age 3 , and a further decline to $29 \%$ at age 4 (Table 3). Overall, from baseline to two-year follow-up, the children in this study sample experienced a $39.5 \%$ reduction in the prevalence of stunting malnutrition and a modest but significant increase in mean HAZ. Examining the changes in rates of stunting malnutrition by the children's age of entry into the intervention shows reductions in stunting malnutrition for every age cohort except those entering the two-year-old group, the peak of stunting in this population. Examining the changes in rates of stunting malnutrition by the children's caries increment reveals that children in the medium-caries increment group experienced the most significant reductions in stunting-a $54.3 \%$ reduction in stunting prevalence and a moderate increase in mean HAZ (Table 4). The low-caries increment group experienced a significant reduction in stunting prevalence, but no significant improvement in mean HAZ; and the high-caries
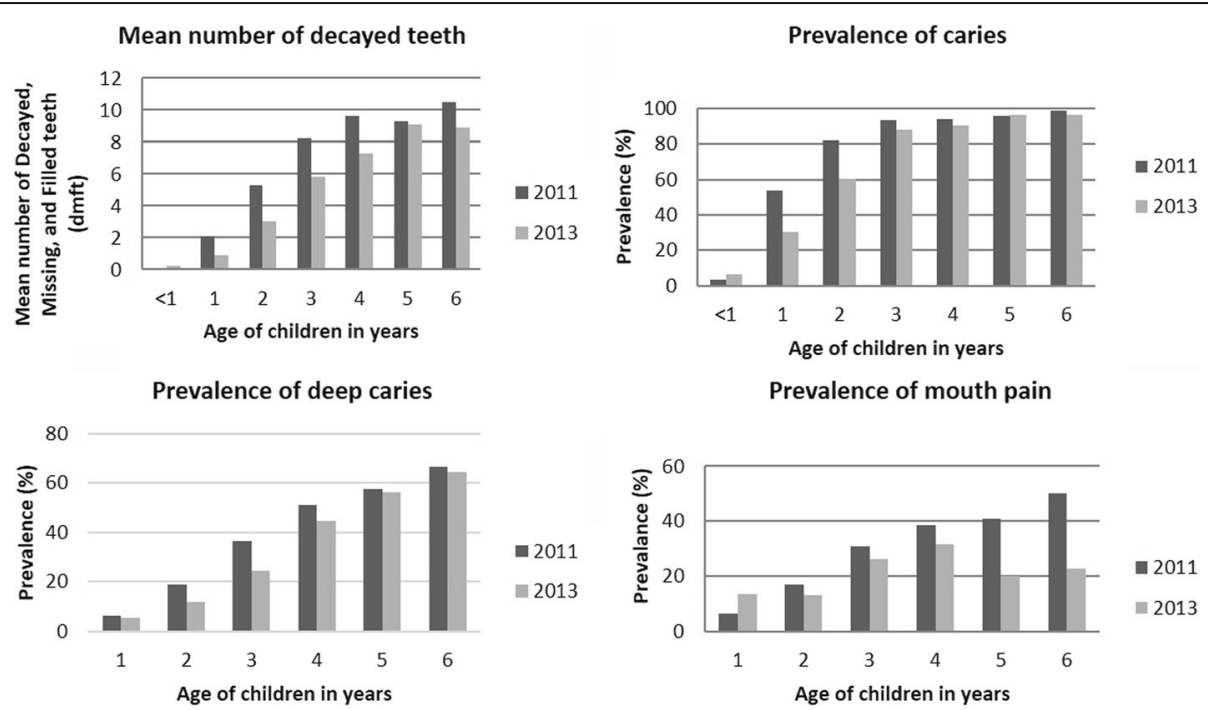

Fig. 2 Early Childhood Caries Experience by Age and Study Year. A combination of four bar-graphs showing; Mean number of teeth decayed by age, prevalence of caries by age, prevalence of deep caries by age and prevalence of mouth pain by age 
Table 2 Caries Experience and Malnutrition from Baseline to 2-year Follow-up (Cross-sectional and Longitudinal samples) ${ }^{a}$

\begin{tabular}{|c|c|c|c|c|c|c|}
\hline \multirow{2}{*}{ Caries Experience } & & \multicolumn{2}{|c|}{ Baseline (2011) } & \multicolumn{2}{|c|}{ Follow-up (2013) } & \multirow[t]{2}{*}{$p$ value } \\
\hline & & $\mathrm{N}$ & \%/Mean & $\mathrm{N}$ & \%/Mean & \\
\hline \multirow[t]{3}{*}{ Caries Prevalence } & $0-6$ years Cross-sectional & 595 & $81.3 \%$ & 546 & $78.0 \%$ & 0.070 \\
\hline & 2-4 years-old Cross-sectional & 293 & $89.9 \%$ & 247 & $80.2 \%$ & $<0.001$ \\
\hline & 2-4 years-old Longitudinal & 100 & $93.5 \%$ & 63 & $86.3 \%$ & 0.089 \\
\hline \multirow[t]{3}{*}{ Mean dmft } & $0-6$ years Cross-sectional & 731 & 7.3 (SD 5.4) & 698 & 6.1 (SD 4.7) & $<0.001$ \\
\hline & 2-4 years Cross-sectional & 326 & 7.7 (SD 5.0) & 308 & $5.3(S D$ 3.2) & $<0.001$ \\
\hline & 2-4 years Longitudinal & 110 & $8.2(S D 4.8)$ & 123 & $6.2(\mathrm{SD} 4.1)$ & 0.024 \\
\hline \multirow[t]{3}{*}{ Prevalence of Deep decay } & $0-6$ years Cross-sectional & 287 & $39.2 \%$ & 256 & $36.6 \%$ & 0.165 \\
\hline & $2-4$ years Cross-sectional & 116 & $35.6 \%$ & 82 & $26.6 \%$ & 0.009 \\
\hline & 2-4 years Longitudinal & 34 & $31.8 \%$ & 25 & $34.2 \%$ & 0.425 \\
\hline \multirow[t]{3}{*}{ Prevalence of Mouth pain } & $0-6$ years Cross-sectional & 221 & $30.2 \%$ & 145 & $20.8 \%$ & $<0.001$ \\
\hline & $2-4$ years Cross-sectional & 94 & $28.8 \%$ & 73 & $23.7 \%$ & 0.084 \\
\hline & 2-4 years Longitudinal & 40 & $37.4 \%$ & 23 & $31.5 \%$ & 0.258 \\
\hline \multirow{3}{*}{$\begin{array}{l}\text { Prevalence of any Restorative } \\
\text { Treatment }\end{array}$} & $0-6$ years Cross-sectional & 163 & $22.3 \%$ & 192 & $27.5 \%$ & 0.014 \\
\hline & $2-4$ years Cross-sectional & 46 & $14.1 \%$ & 54 & $17.5 \%$ & 0.142 \\
\hline & 2-4 years Longitudinal & 18 & $16.8 \%$ & 18 & $24.7 \%$ & 0.136 \\
\hline \multirow[t]{3}{*}{ Mean number of untreated lesions } & $0-6$ years Cross-sectional & 731 & $6.2(\mathrm{SD} 5.0)$ & 698 & $5.2(\mathrm{SD} 4.3)$ & $<0.001$ \\
\hline & $2-4$ years Cross-sectional & 326 & 7.4 (SD 4.9) & 308 & 4.9 (SD 3.9) & $<0.001$ \\
\hline & 2-4 years Longitudinal & 110 & 7.8 (SD 4.8) & 123 & $5.5(S D$ 3.9) & 0.001 \\
\hline \multicolumn{7}{|l|}{ Malnutrition } \\
\hline \multirow[t]{3}{*}{ Stunting prevalence $\mathrm{HAZ}<-2 \mathrm{Z}$} & $0-6$ years Cross-sectional & 22 & $30.6 \%$ & 198 & $24.8 \%$ & 0.183 \\
\hline & $2-4$ years Cross-sectional & 113 & $34.7 \%$ & 99 & $32.1 \%$ & 0.278 \\
\hline & 2-4 years Longitudinal & 46 & $43.0 \%$ & 21 & $28.8 \%$ & 0.037 \\
\hline \multirow[t]{3}{*}{ Underweight prevalence $W A Z<-2 Z$} & $0-6$ years Cross-sectional & 53 & $7.3 \%$ & 40 & $5.7 \%$ & 0.144 \\
\hline & $2-4$ years Cross-sectional & 19 & $5.8 \%$ & 16 & $5.2 \%$ & 0.431 \\
\hline & 2-4 years Longitudinal & 4 & $3.7 \%$ & 2 & $2.7 \%$ & 0.533 \\
\hline
\end{tabular}

${ }^{\mathrm{a}} 2-4$ year old age group were selected for analysis in order to provide better comparability between the longitudinal sample and the cross-sectional sample

increment group did not experience significant reduction in the prevalence of stunting, although they experienced a modest but significant improvement in mean HAZ.

To further assess the reductions in malnutrition rates in the longitudinal sample, the "observed" rates of malnutrition at each age group (i.e., the prevalence of malnutrition in the study sample at 2-year follow-up) were compared to the population's "expected" rate of malnutrition at each age group (i.e., the prevalence of malnutrition in the study sample at baseline in 2011), or this population's "historical control." At two-year followup, this cohort showed substantially lower rates of stunting malnutrition compared to the expected rates at two and three years of age, corresponding to entry into the intervention in the first two years of life (Fig. 3). Children who entered the program before one year of age experienced one-quarter less stunting at two years of age than expected (from 61 to 47\%); and those who entered between one and two years had one-half the rate of stunting than expected at three years of age (from 40 to $19 \%)$. For children who entered the program after age two, and were age 4 at follow-up, reductions from the expected rates of stunting were not seen.

\section{Discussion}

This study examined the caries experience and nutritional status of children from birth through six years of age who participated in a community-based preventive oral health and nutrition intervention in Pueblo Kichwa, an indigenous rural community in the Amazonian region of Ecuador. There were significant improvements in children's dental caries experience and nutritional status over time.

\section{Caries experience}

The children in this population were found to have a high prevalence and severity of ECC, beginning in the first year of life and increasing steadily thereafter, which is consistent with other studies in the region [21]. Studies of other indigenous populations in North America and Australia 
Table 3 Longitudinal Analysis of Stunting Malnutrition, by Child's Age of Entry into Intervention

\begin{tabular}{|c|c|c|c|c|c|c|}
\hline \multicolumn{7}{|c|}{ Number (\%) Children with Stunting Malnutrition, $\mathrm{HAZ}<-2 \mathrm{Z}$} \\
\hline \multicolumn{2}{|l|}{ Baseline (2011) } & \multicolumn{2}{|c|}{ Follow-up (2013) } & \multicolumn{3}{|l|}{ Observed change } \\
\hline $\begin{array}{l}\text { Child age of entry } \\
\text { and at exam }\end{array}$ & $H A Z<-2 Z$ & Age at exam & $H A Z<-2 Z$ & Absolute change & Proportional change $^{a}$ & $\begin{array}{l}\text { P-Value Observed } \\
\text { Change }^{b}\end{array}$ \\
\hline$<1$ year & 7 (36.8\%) & 2 years & $8(47.1 \%)$ & $+10.3 \%$ & $+28.0 \%$ & $\begin{array}{l}0.688 \\
0.414\end{array}$ \\
\hline 1 year & $13(40.6 \%)$ & 3 years & $6(18.6 \%)$ & $-22.0 \%$ & $-54.2 \%$ & $\begin{array}{l}0.065 \\
0.035\end{array}$ \\
\hline 2 years & $19(61.3 \%)$ & 4 years & $11(42.3 \%)$ & $-19.0 \%$ & $-31.0 \%$ & $\begin{array}{l}0.180 \\
0.096\end{array}$ \\
\hline 3 years & $18(40.0 \%)$ & 5 years & $10(25.0 \%)$ & $-15.0 \%$ & $-37.5 \%$ & $\begin{array}{l}0.070 \\
0.034\end{array}$ \\
\hline 4 years & $9(29.0 \%)$ & 6 years & $5(16.7 \%)$ & $-12.3 \%$ & $-42.4 \%$ & $\begin{array}{l}0.453 \\
0.257\end{array}$ \\
\hline Total 0-4 years & 66 (41.0\%) & $2-6$ years & 40 (24.8\%) & $-16.2 \%$ & $-39.5 \%$ & $\begin{array}{l}0.005 \\
0.003\end{array}$ \\
\hline
\end{tabular}

${ }^{a}$ Calculated by dividing the change in prevalence by the baseline prevalence and expressing it as a percentage

${ }^{\mathrm{b}} \mathrm{P}$-values presented are based on McNemar test (first) and Cochran's $\mathrm{Q}$ test (second)

have also shown that ECC is a near-universal and commonly severe experience by five-to six-years of age [22].

The most prominent risk factor for ECC in this population was the rapid access to stores that sold junk food-despite the rural setting and limited resources, three quarters of families could access junk food within a five-minute walk from their house, and nearly half of children reportedly consumed junk food at least once a day. The rapid access, low cost and widespread advertisement of junk food to children has been found to drive the high frequency of junk food consumption [25]. This study found a reduction in the parent-reported consumption of junk food, although it is difficult to know how this corresponds to actual behavior change.

The greatest reduction in caries experience was found for the children who entered the intervention in the first year of life, who started on a less-severe trajectory for caries development. Nutrition and oral hygiene habits tend to be established early, and it is easier to establish healthy behaviors from birth than to reverse unhealthy behaviors later in childhood [26].

The greatest reduction in mouth pain was seen for children at five-to six-years of age, who had the greatest burden of caries and received the most dental treatment. While a substantial proportion of children's mouth pain in the first two years of life may result from non-caries causes such as normal teething and other oral infections, caries-related mouth pain in older children may be under-reported if they suffer from chronic pain and do not articulate their pain experience [27].

Tragically, a large burden of disease remained. It is critical for interventions to address the high prevalence of severe caries and caries-related mouth pain in early childhood, which can seriously impair children's quality of life, nutrition, growth, development and educational potential [11]. Once a carious lesion becomes cavitated, it may be difficult to manage with toothbrushing and fluoride varnish alone, and further benefit could be gained through arrest-of-caries treatment with silver compounds [28].

The WHO has declared a goal of reducing the prevalence of any dental caries in five- and six-year-old children to less than $50 \%$ [16]. Given that the one-yearolds in this population already had over 50\% caries prevalence, intensive prevention of ECC would need to begin before age one.

\section{Malnutrition and caries}

The high rate of stunting malnutrition found in this study was consistent with other reports $[18,19]$. Children in the longitudinal subsample-who had poorer health at baseline, and attended all three dental camps-demonstrated greater nutritional improvements than those in the crosssectional sample. Children who entered the intervention during the first two years of life realized the greatest reductions in stunting malnutrition, exceeding expected changes. This finding agrees with other studies showing that interventions to reduce stunting malnutrition are effective only prior to two years of age [29]. We hypothesize that some of the malnutrition in this population was associated with factors targeted by this intervention, e.g., frequent consumption of junk food instead of healthy nutrients, and severe early childhood caries involving acute and chronic infection/inflammation and mouth pain, which are known to inhibit appetite, eating ability, sleep and growth [30]. The low prevalence of underweight and wasting malnutrition in this population made the study under-powered for observing significant changes in those nutritional indicators. 
Table 4 Longitudinal Analysis of Stunting Malnutrition, by Child Caries Increment

\begin{tabular}{|c|c|c|c|c|c|c|c|c|c|c|c|c|c|c|}
\hline \multirow[t]{3}{*}{ Caries Increment } & \multicolumn{7}{|c|}{ Number (\%) of Children with $\mathrm{HAZ}<-2 \mathrm{Z}$} & \multicolumn{7}{|c|}{ Mean HAZ score (SD) } \\
\hline & \multicolumn{2}{|c|}{ Baseline } & \multicolumn{2}{|c|}{ Follow-up } & \multirow{2}{*}{$\begin{array}{l}\text { Absolute change } \\
\%\end{array}$} & \multirow{2}{*}{$\begin{array}{l}\text { Proportionate change } \\
\%\end{array}$} & \multirow[t]{2}{*}{$P$-value } & \multicolumn{2}{|c|}{ Baseline } & \multicolumn{2}{|c|}{ Follow-up } & \multirow{2}{*}{$\begin{array}{l}\text { Mean } \\
\text { change }\end{array}$} & \multirow{2}{*}{$\begin{array}{l}\text { Effect } \\
\text { size }^{c}\end{array}$} & \multirow[t]{2}{*}{$P$-value } \\
\hline & $\bar{N}$ & $\%$ & $\mathrm{~N}$ & $\%$ & & & & Mean & SD & Mean & SD & & & \\
\hline Low (0-2 dmft/year) & 28 & 48.3 & 16 & 29.1 & -19.2 & -39.8 & $\begin{array}{l}0.064 / \\
0.039\end{array}$ & -1.6 & 1.3 & -1.6 & 1.0 & 0.0 & 0.0 & 0.070 \\
\hline Medium (3-5 dmft/year) & 16 & 39.0 & 7 & 19.4 & -19.6 & -54.3 & $\begin{array}{l}0.065 / \\
0.035\end{array}$ & -1.7 & 0.9 & -1.3 & 0.8 & +0.4 & 0.4 & 0.003 \\
\hline High ( $\geq 6$ dmft/year) & 22 & 35.5 & 17 & 29.8 & -5.7 & -16.1 & $\begin{array}{l}0.549 / \\
0.366\end{array}$ & -1.6 & 1.0 & -1.5 & 0.9 & +0.1 & 0.1 & 0.030 \\
\hline Total & 66 & 41.0 & 40 & 24.8 & -16.2 & -39.5 & $\begin{array}{l}0.005 / \\
0.003\end{array}$ & -1.6 & 1.1 & -1.5 & 0.9 & +0.1 & 0.1 & $<0.001$ \\
\hline
\end{tabular}

a Calculated by dividing the change in prevalence by the baseline prevalence and expressing it as a percentage ${ }^{\mathrm{b}} P$-values presented are based on McNemar test (first) and Cochran's $Q$ test (second)

'Effect size; $0.2-0.4$ is considered to be 'small'; $0.5-0.7$ is 'Moderate'; and more than 0.8 is considered to be 'large'

${ }^{\mathrm{d}} P$-values presented are based on Wilcoxon rank sum test 


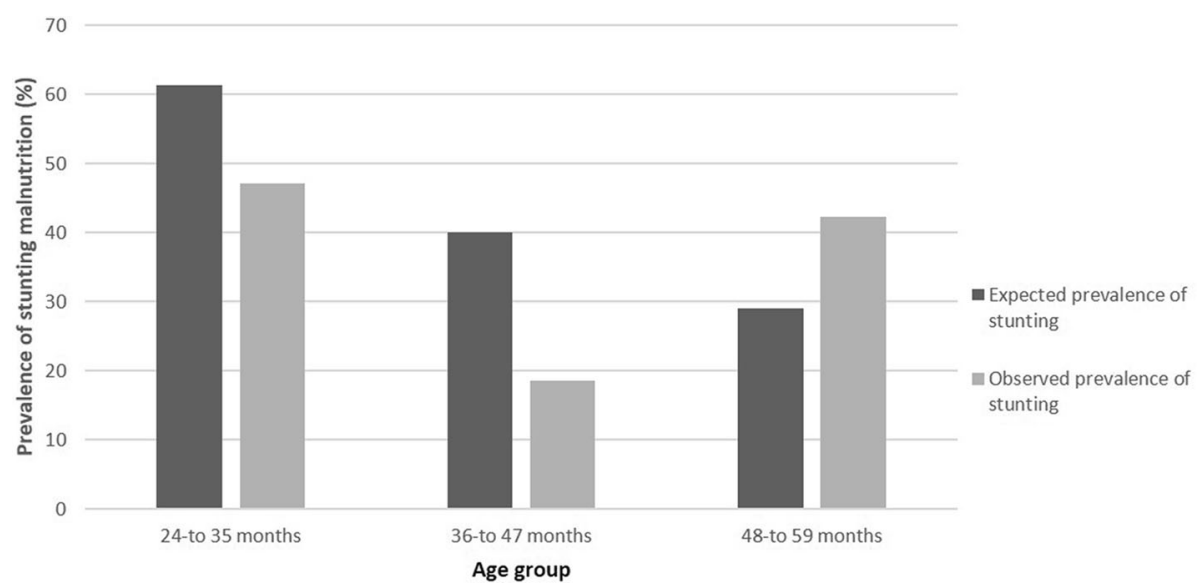

Fig. 3 Expected and Observed Stunting Malnutrition by Age Group in the Longitudinal Sample. A bar graph showing expected and observed prevalence of stunting malnutrition across three age groups. Includes subscript text as follows: "Expected" prevalence of stunting is the prevalence of malnutrition by age group in the longitudinal sample, measured at baseline (2011); "Observed" prevalence of stunting is the prevalence of malnutrition by age group in the longitudinal sample, measured at the 2-year follow-up (2013)

Similar to the well-known health care concept of "triage," there was a subgroup of children who achieved the greatest benefit from this intervention, the "medium" caries- increment group. Those children may have experienced caries-related malnutrition that was effectively treated with this oral health intervention. On the other hand, children in the high-caries increment group, whose caries disease process was less controlled, may need a more intensive dental case management and treatment to improve their oral health and nutrition. In contrast, children in the low-caries increment group, who began with a higher prevalence of malnutrition, likely had other non-caries related causes for malnutrition, and may need more intensive nutritional interventions such as food and micronutrient supplementation, and treatment for infectious diseases. This population of children had many causes of malnutrition that our oral health intervention was not designed to address; however, we observed substantial improvements in their nutritional status associated with the prevention and management of tooth decay, without providing additional food, micronutrients or medical treatment.

This study's findings are novel since neither global nor local studies on child malnutrition have cited early childhood caries as a contributor to malnutrition, nor caries prevention and treatment as strategies for reducing malnutrition $[1,18]$. A randomized controlled trial could further test the hypothesis that community-wide education for families on healthier food choices and implementation of low-cost measures to prevent the caries process (including chronic inflammation and mouth pain) could improve children's nutritional status by improving their appetite and helping them to eat, metabolize and grow utilizing the food that is available to them. Longitudinal trials could also test the hypothesis that a six-year follow-up, carrying the birth cohort to school-age, could continue to show a healthier trajectory with substantially lower rates of caries, mouth pain and malnutrition across the early childhood years, rendering more children caries-free, pain-free and ready to learn when they enter school at five to six years of age.

\section{Limitations and strengths of the study}

The convenience sampling of approximately $45-70 \%$ of the preschool-age population in the area and the high drop-out rate in the longitudinal cohort may limit the generalizability of the results. The study did not follow a contemporaneous control or comparison group due to limited resources and concerns about the ethics of withholding the intervention from children in need, and instead compared our follow-up results to historical preintervention 'controls' from the same population. As a population-wide intervention, there was inevitably clustering at the family- and community-wide level, for which this preliminary analysis did not account. While this sampling was vulnerable to sampling bias, the methodology represents a realistic community-based intervention in a logistically-challenging environment where some families follow the entire program and others may not. Although many children could not be examined on the designated annual follow-up day due to the families' logistical challenges (e.g., torrential rain, lack of transportation, family illnesses, work obligations, and not prioritizing the follow-up exam if their child was cavity-free and pain-free), most children and families continued to receive the intervention through their community and preschool. 
The strengths of this study lay in the strong partnership with community leaders and local health and education institutions; and the ability to conduct a population-wide, low-cost, preventive intervention, over multiple years. The results of this community intervention highlight the need for further investigation into the relationship between caries and under-nutrition, including conventional randomized controlled study designs.

\section{Conclusions}

This community-wide study of the oral health and nutrition of indigenous children from birth to age six in rural Ecuador found high baseline rates of junk food consumption, early childhood caries, mouth pain and stunting malnutrition. The two-year follow-up of our low-cost, community-wide preventive intervention-involving nutrition/oral health education, toothbrushes, fluoride toothpaste, fluoride varnish, and dental treatment- showed significant reductions in early childhood caries experience and malnutrition. Our cross-sectional and longitudinal analyses demonstrated that the children who began the intervention in the first two years of life experienced the greatest benefits. This study underscores the importance of universal, community-wide programs to jointly address oral health and nutrition. Given the near-universal access to prenatal care and early childhood immunizations, maternal-child health and nutrition programs should consider incorporating oral health interventions, starting from pregnancy and birth.

\section{Abbreviations}

ECC: Early childhood caries; DMFT: Decayed, missing, or filled teeth; HAZ: Height-for-age Z-score; WAZ: Weight-for-age Z-score; WHO: World Health Organization

\section{Acknowledgements}

We would like to express our profound appreciation to the Pueblo Kichwa leaders and community members who believed in the healthfulness of their traditional diet, and "Alli kiru, kushi wawakuna" (Healthy teeth, happy children). A special thanks to Bethy Shiguango, Martha Husby, Rebecca Peterson and Richard Miller for helping to coordinate the program; the Kichwa health volunteers, preschool teachers from La Red de Educación Bilingüe and Instituto de la Niñez y la Familia, and the Ministry of Health dentists who implemented the intervention; Drs. Linda Low, Amparito Ibarra and Caroline Peterson for their clinical expertise; Ines Coquinche for Kichwa translation; Jeffrey Allen for data management; dozens of US and Ecuadorean volunteers who worked on this program; and the Municipio de Archidona for transportation. Many thanks for generous funding for the intervention from Rotary International, University of California Pacific Rim Research Initiative, American Academy of Pediatrics I-CATCH, and many family members and friends; for donation of dental supplies from Global Grins, Sunstar/GumBrands, America's Tooth Fairy, Varnish America, 3 M, Voco, Cavity Shield, Centrix, Premier, EnameIPro, Patterson Dental, and Dr. Finn Tonsberg; and for donation of children's clothes and toys from Bambino Thrift Shop.

\section{Funding}

The project received multiple sources of funding. Funders were Rotary International, University of California Pacific Rim Research Initiative, American Academy of Pediatrics I-CATCH. There were also donations of dental supplies from Global Grins, Sunstar/GumBrands, America's Tooth Fairy, Varnish America, 3 M, Voco, Cavity Shield, Centrix, Premier, EnamelPro, Patterson Dental, and Dr. Finn Tonsberg; and for donation of children's clothes and toys from Bambino
Thrift Shop. None of these parties had any role in the study design, data collection, analysis or interpretation of the data.

\section{Availability of data and materials}

The datasets used and/or analysed during the current study available from the corresponding author on reasonable request.

\section{Authors' contributions}

KSG designed the study, obtained funding, co-led the collaboration with the local partners, co-supervised the intervention and data collection, guided and reviewed the data analysis, and drafted the manuscript. BT participated in data collection in 2013, conducted the statistical analysis, produced the tables and figures, and helped draft and revise the manuscript. HH recruited the community partners, coordinated the collaboration and data collection onsite, and reviewed the manuscript. CLP coordinated the dental intervention and data collection onsite, led collaboration with the local Ministry of Health partners, and reviewed the manuscript. All authors read and approved the final manuscript.

\section{Authors' information}

The affiliations of the authors are listed in on the title page.

\section{Competing interests}

The authors declare that they have no competing interests.

\section{Consent for publication}

Not Applicable - This manuscript does not contain any individual person's data as there are no individual details, images or videos.

\section{Ethics approval and consent to participate}

This research involved human subjects and as such it was performed in accordance with the Declaration of Helsinki. The caregivers of the participants gave consent for children to participate. The study received approval by the Institutional Review Board at the University of California, Berkeley (2011-04-3178).

\section{Author details}

1School of Public Health, University of California, Berkeley, 570 University Hall, MC 1190, Berkeley CA 94720, USA. ²University Puthisastra, Phnom Penh, Cambodia. ${ }^{3}$ School of Public Health, University of California, Los Angeles, USA. ${ }^{4}$ Pasaje José Lúcuma E6-163 y Pedro Cornelio, urbanización Bonanza, Quito, Ecuador.

Received: 30 March 2016 Accepted: 18 November 2016 Published online: 29 November 2016

\section{References}

1. Black RE, Victoria CG, Walker SP, Bhutta ZA, Christian P, de Onis M. Maternal and child undernutrition and overweight in low-income and middle-income countries. Lancet. 2013:382:427-51.

2. Popkin BM, Gordon-Larsen P. The nutrition transition: worldwide obesity dynamics and their determinants. Int J Obes. 2004;28 Suppl 2:2-9.

3. Hooley M, Skouteris H, Boganin C, Satur J, Kilpatrick N. Parental influence and the development of dental caries in children aged 0-6 years: a systematic review of the literature. J Dent. 2012;40:873-85.

4. Kassebaum NJ, Bernabé E, Dahiya M, Bhandari B, Murray CJL, Marcenes W. Global burden of untreated caries a systematic review and metaregression. J Dent Res. 2015;94:650-8. doi:10.1177/0022034515573272.

5. Fejerskov O, Kidd E. Dental caries: the disease and its clinical management. $2^{\text {nd }}$ ed. Oxford: Wiley; 2009.

6. Sheiham A, James WPT. Diet and dental caries the pivotal role of free sugars reemphasized. J Dent Res. 2015;94:1341-7.

7. Benzian H, Monse B, Heinrich-Weltzien R, Hobdell M, Mulder J, van Palenstein Helderman W. Untreated severe dental decay: a neglected determinant of low body mass index in 12-year-old Filipino children. BMC Public Health. 2011;11:558-67.

8. Sheiham A. Dental caries affects body weight, growth and quality of life in pre-school children. Br Dent J. 2006;201:625-6.

9. Monse B, Heinrich-Weltzien R, Benzian H, Holmgren C, van Palenstein Helderman W. PUFA-An index of clinical consequences of untreated dental caries. Community Dent Oral Epidemiol. 2010;38:77-82. 
10. Alkarimi HA, Watt RG, Pikhart H, Jawadi AH, Sheiham A, Tsakos G. Impact of treating dental caries on schoolchildren's anthropometric dental, satisfaction and appetite outcomes: a randomized controlled trial. BMC Public Health. 2012;12:706-13.

11. McGrath C, Broder H, Wilson-Genderson M. Assessing the impact of oral health on the life quality of children: implications for research and practice. Community Dent Oral Epidemiol. 2004;32:81-5.

12. Hahn C-L, Liewehr FR. Relationships between caries bacteria, host responses, and clinical signs and symptoms of pulpitis. J Endod. 2007;33:213-9.

13. Alvarez JO. Nutrition, tooth development, and dental caries. Am J Clin Nutr. 1995;61:410-6.

14. Sheiham A, Watt RG. The common risk factor approach: a rational basis for promoting oral health. Community Dent Oral Epidemiol. 2000;28:399-406.

15. Acs G, Pretzer S, Foley M, Ng MW. Perceived outcomes and parental satisfaction following dental rehabilitation under general anesthesia. Pediatr Dent. 2001;23:419-23.

16. Allukian Jr M. The neglected epidemic and the surgeon general's report: a call to action for better oral health. Am J Public Health. 2000;90:843.

17. Slade GD, Bailie RS, Roberts-Thomson K, Leach AJ, Raye I, Endean C, et al. Effect of health promotion and fluoride varnish on dental caries among Australian Aboriginal children: results from a community-randomized controlled trial. Community Dent Oral Epidemiol. 2011;39:29-43.

18. Walker I, Marini A, Lucchetti L, Waters W, Lastra A. Nutritional failure in Ecuador: causes consequences and solutions. The World Bank. 2007. http://www.popline.org/node/191935. Accessed 23 Nov 2016.

19. Rogers BL, Wirth J, Macías K, Wilde P. Mapping hunger in Ecuador: a report on mapping malnutrition prevalence. Friedman School of Nutrition Science and Policy. 2007 http://www.researchgate.net/profile/James_Wirth/ publication/5057577_Mapping_Hunger_in_Ecuador_A_Report_on_ Mapping_Malnutrition_Prevalence/links/0046352540d8853888000000.pdf. Accessed 23 Nov 2016

20. Pan American Health Organization. 2016. http://www.paho.org/ saludenlasamericas/index.php?option=com_docman\&task=doc_view\&gid= 128\&ltemid=. Accessed 23 Nov 2016.

21. Bönecker $\mathrm{M}$, Cleaton-Jones $\mathrm{P}$. Trends in dental caries in Latin American and Caribbean 5-6-and 11-13-year-old children: a systematic review. Community Dent Oral Epidemiol. 2003;31:152-7.

22. Medina W, Hurtig A-K, San Sebastián M, Quizhpe E, Romero C. Dental caries in 6-12-year-old indigenous and non-indigenous schoolchildren in the Amazon basin of Ecuador. Braz Dent J. 2008;19:83-6.

23. WHO / Oral health surveys: basic methods - 5th edition. WHO. 2014. http:/www. who.int/oral_health/publications/9789241548649/en/. Accessed 23 Nov 2016.

24. Eveleth PB. Physical status: the use and interpretation of anthropometry. Report of a WHO Expert Committee. Am J Hum Biol. 1996;8:786-7.

25. Cairns G, Angus K, Hastings G, Caraher M. Systematic reviews of the evidence on the nature, extent and effects of food marketing to children. A retrospective summary. Appetite. 2013;62:209-15.

26. Gussy MG, Waters EG, Walsh O, Kilpatrick NM. Early childhood caries: current evidence for aetiology and prevention. J Paediatr Child Health. 2006;42:37-43.

27. Wallander $\mathrm{JL}$, Schmitt M, Koot HM. Quality of life measurement in children and adolescents: issues, instruments, and applications. J Clin Psychol. 2001;57:571-85.

28. Rosenblatt A, Stamford TC, Niederman R. Silver diamine fluoride: a caries "silver-fluoride bullet". J Dent Res. 2009;1 (88):116-25.

29. Bhutta ZA, Ahmed T, Black RE, Cousens S, Dewey K, Giugliani E, et al. What works? Interventions for maternal and child undernutrition and survival. Lancet. 2008;371:417-40.

30. Khanh LN, Ivey SL, Sokal-Gutierrez K, Barkan H, Ngo KM, Hoang HT, et al. Early childhood caries, mouth pain and nutritional threats in Vietnam. Am Journal Public Health. 2015;105(12):2510-7.

\section{Submit your next manuscript to BioMed Central and we will help you at every step:}

- We accept pre-submission inquiries

- Our selector tool helps you to find the most relevant journal

- We provide round the clock customer support

- Convenient online submission

- Thorough peer review

- Inclusion in PubMed and all major indexing services

- Maximum visibility for your research

Submit your manuscript at www.biomedcentral.com/submit
Biomed Central 